\title{
Toward Nature-Based Solutions (NBS) Approach in Integrated Segment Reporting of Placed-Based Organizations
}

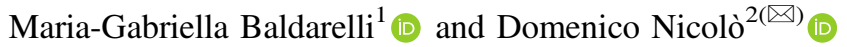 \\ ${ }^{1}$ University of Bologna, 40126 Bologna, Italy \\ 2 University Mediterranea of Reggio Calabria, 89124 Reggio Calabria, Italy \\ domenico.nicolo@unirc.it
}

\begin{abstract}
This paper aims to focus on the contribution of the approach by segments of place-based organizations to planning and reporting social and environmental performance along with economic and financial dimensions. The literature review is about Nature-Based Solutions (NBS) and segment reporting. In the context of scientific contributions regarding the NBS approach, an important issue is to evaluate the impact of NBS about different social and environmental challenges. Raymond et al. (2017) propose a framework to identify how NBS can produce both synergies through ecosystem services and co-benefits in a NBS view. Moreover, the paper analyses the logic underlying the technique of segmentation in the "space", the social performance of the operating segments over "time" and the synergies between segments. In the case examined (a Farm), we will demonstrate how the case manages to achieve significant economy with the production of electric energy deriving from the biogas obtained by fermentation of manure, therefore it does not incur the cost of purchasing electricity and it doesn't incur in the disposal costs of the manure, but to translate them into raw material to produce electricity and also to sell the energy in excess to its needs. Besides, the Farm generates benefits for the environment inside and outside of it.
\end{abstract}

Keywords: Nature based solutions $\cdot$ Segment reporting $\cdot$ Environmental impact $\cdot$ Farm analysis $\cdot$ Value added

\section{Introduction}

In the past, the debate had developed with fierce criticisms over the behavior of transnational companies, which have given rise to and continue to perpetrate greenwashing behaviors without highlighting an effective change in production systems. Systems that are not yet able to guarantee respect for the environment and its improvement. In practice, instead, a marketing process oriented towards greenwashing is developed, which is also accompanied by a "discreet" intervention strategy at the

This paper is the result of joint research; however, M.G. Baldarelli wrote the Introduction, Sects. 2, 4 and the Discussion and Conclusion; D. Nicolò wrote Sects. 3 and 5.

(C) The Author(s) 2020

C. Bevilacqua et al. (Eds.): NMP 2020, SIST 177, pp. 101-112, 2020.

https://doi.org/10.1007/978-3-030-52869-0_9 
political level and also by international organizations to make it possible, however, to make a greater profit for each company with the illusion that they implement them in environmentally friendly projects [1].

Since some classic business economics authors analyzed farms, including Giannessi [2] and Besta [3], the situation in which they operate has completely changed and requires reflection on the company-environment relationship. For this reason, we try to interpret NBS within a territorial context as well as it relating to farms, despite being a theory applied to urban areas through the correlation with the NBS. In this context, the role of accountability [4-9] is very important, because it is a process that allows all companies to acquire legitimacy from the stakeholders who employ certain tools, including segment reporting, which are outlined in this work.

Moreover, this paper has the objective of answering the research question: How to write segment reporting by NBS perspective?

The research design involves the deductive [10] and inductive approach [11]. The deductive approach is analyzing the literature review in two ways. The first step is the presentation of Nature Based Solutions (NBS) to create a wider framework to construct further analysis. The second step is considering the presentation of the theory of segment reporting. The inductive approach regards implementation of segment reporting using the research case of Fattoria della Piana (Italy).

The research case is very important, because it involves a vast area of the territory and for this reason may be termed: a place-based organisation. The research case, that is a farm, is based on internal and external NBS, as it can simultaneously relate cost savings and the supply of production factors, because it will be demonstrated how biogas allows for the direct production of electricity for self-consumption. In the case examined, we will demonstrate how the case manages to achieve significant economy with the production of electric energy deriving from the bio-gas obtained by fermentation from animal excrement, therefore it does not incur the cost of purchasing electricity and it does not incur disposal costs of the excrement of the animals rather to use them as fuel to produce electricity and also to sell the energy in excess relevant to its needs. Similarly, with waste-water that the firm refines by phytodepuration and uses to irrigate the fields that produce animal feed. The circularity of the economy is put on the net, creating differential economic, social and environmental advantages. In addition, the Farm generates benefits for the environment, creating a NBS both inside and outside of it.

The paper is divided into the following sections: the first one concerns the literature review relating to NBS; the second section regards segment reporting analysis; the third section concerns the results of the case analysis and the forth section regards discussion and conclusion.

\section{Nature Based Solutions (NBS) as Framework to Pass from Greenwashing to Green?}

NBS is primarily designed for nature-based and eco-system solutions at an urban level in order to create improvements in the harmony existing among: environment, space, structures and human beings. It is a very wide framework to place our analysis in and 
which involves an interdisciplinary approach and in this paper we are going to use only some areas of the this theory. To introduce NBS the definition framework indicates that: "NBS explicitly address societal challenges. The solutions are not aimed at addressing only environmental challenges or minimizing only environmental impacts, although these may be part of what the NBS is targeting "produces societal benefits in a fair and equitable way, in a manner that promotes transparency and broad participation" [12].

Among the different themes and guidelines, that are proposed by Raymond et al. 2017, we focus our attention mainly on two areas. The first area concerns: "benefits and co-benefits for human health and well-being" and the second area regards: "integrated environmental performances; costs, trade-offs, benefits and co-benefits for biodiversity, economy and community" [13]. The meaning of the first area is to create improvement in the quality of life using relationships and co-creation opportunities to create an emancipatory change. The meaning of the second area is that of developing the emancipatory change that is necessary to activate the process in order to measure, record and monitor the performances of project implementation. Especially for companies this process is very important to avoid green-washing and to move to real environmentally friendly change. These areas are divided into other more specific ones, because the objective is to create projects that implement this general theory and to develop indicators that will be able to monitor the level of application of the theory. The first area involves deeper specific sub-areas, which allow for a better articulation and possible, subsequent control of the qualitative and quantitative information that may derive from them. Among the specific areas, we can highlight that one relating to water management, which represents a fundamental resource for agricultural companies both as regards food and also regarding irrigation. The second specific area, of special interest for this paper, is also attention to human health and quality of life which, in the case of farms, extends to that of animals. The third specific area relates to the management of the impact on the climate, which requires cutting-edge technologies for the recycling of materials, the reuse of the same as also suggested by the integrated and NBS. Moreover, NBS is primarily designed for nature-based and eco-system solutions on the urban level. In this paper, on the other hand, we want to extend the reflection that derives from NBS to the level of even rural territories. Actually, as regards measurement and monitoring of the first NBS area, it is necessary to underline the importance of organic production and breeding that respect both the size of the spaces for animals and the rhythm and natural seasons that we will find in the research case. This means that the criteria for using natural fertilizers and cultures are respected in the production chain, even those used as food for animals follow the logic of the biological circuit. The second area, which is related to integrated environmental performances, requires the structuring of an information system [14], that is described in the case analysed, to be able to quickly and reliably measure the external and internal impact of the aspects related to cultures and breeding considering the costs and benefits deriving from respect of the environment. Within this, the management of the agricultural territory is particularly relevant, which is in close connection with the company and therefore the protection of the same is important to make it usable with the same effectiveness for future generations too. To reach this objective some more specific drivers and models are required. We will involve the following drivers: reduce, reuse, 
recycle and recover $[15,16]$ and the segment reporting model that we are going to analyze in the following paragraph.

\section{Segment Reporting: An Integrated Perspective of Analysis in "Space" and in "Time" of Financial and Social Performance of the Companies}

The operating segments are companies' subsystems resulting from a process of segmentation in "space" in correspondence with the different products, markets, groups of customers, geographical areas, with similar characteristics. Segmentation in "space" leads to the definition of the "map of the segments" and can be carried out according to one of the abovementioned criteria or even a combination of them. The choice of the segmentation criterion (or criteria) depends on the information needs of the management which uses information on the performance of the segments to take decisions and to evaluate the results of the segments and the company as a whole.

Segmentation in "space", by geographical areas and/or by lines of business (LOB), highlights if are there not good performing segments, or even that produce losses. Good performance of the company may hide a bad competitive and/or economic performance of one or more segments. Segmentation in "time", moreover, allows the management of companies to promptly perceive if some segments have an unfavorable financial and/or economic trend, highlighting the need to improve the current trend through targeted choices [17].

Reporting by segment is a source of analytical financial information very useful both for strategic management and external financial disclosure of the companies. Originally to satisfy the information needs of top management, interested in measuring with high frequency (quarterly, monthly) the performance of the segments [18-23], segment reporting has also become a very important part of external financial disclosure [17, 24-27].

Since the international accounting standards (SFAS: 14 and 131; IAS 14 and 14-R; IFRS 8) introduced segment reporting as a mandatory external financial disclosure tool for listed companies, a rich research area has developed on this subject.

The IFRS 8 (Operating segment) has introduced the management approach according to which external reporting by segment for the stakeholders must be based on the same segmentation criteria used for the internal segment reporting addressed to the top management. The underlying idea of this principle is: if a segmentation criterion delivers significant information for management control, it will also be significant to meet the information needs of stakeholders [17, 24, 28-34].

This paper highlights a very important function that can be performed by segment reporting, not yet examined by the literature: measuring the social performance of each segment of the company is very useful in understanding the drivers of the social performance of the company as a whole. In this way, it is easy to find out if there are segments with sub-optimal performance, not only from an economic perspective but also from a social one. The same can be said for the environmental and social dimension of their performance. Furthermore, disclosing the social performance of the 
segments allows stakeholders to know how much value the company produces and distributes, with specific reference to each of their segments as well. Adopting a similar approach, it is also possible to report and manage the company's impact on the environment, with high frequency (monthly, quarterly). In this paper, both from a theoretical point of view and through a case study, these important functions of segment reporting are analysed. The research line suggested by this paper is to combine the social and economic information by segment into an integrated segment reporting [35]. To this end, a segment reporting scheme is proposed. This model is innovative because it integrates two performance dimensions of the segments: both the economic one, highlighted by the operating result of the distinct segments and the social one, expressed by the added value produced by each of them and intended to satisfy the interests of the stakeholders. The value added is assumed as a synthetic indicator of the social performance of the companies and their segments because it shows the wealth distributed to stakeholders (workers, financiers, public administration, shareholders).

The contribution of this paper is to highlight the relevance to measure the contribution of each segment to overall company worth. By measuring the value added created by each segment with high frequency (monthly, quarterly), the management can be informed promptly if some segment does not contribute adequately to the total value added of the company as a whole and set tailored choices to correct any unfavourable trends. For this reason, we propose a reporting by segment scheme which highlights not only the operating result but also the value added created by each segment. This scheme is general and must be tailored by the companies to their specific needs. This model is then applied to a case study in the agri-food sector. In other papers we have presented general reporting schemes for segments that can be adopted by companies operating in other sectors: transport and healthcare [36, 37].

Another contribution of this paper is to propose segment reporting to investigate the synergies between segments and thus highlight the elements of internal synergy (i.e. between segments) and of the ecosystem (between each segment and the environment) that derive from the NBS model adopted in the case-study examined in this paper.

In the case study examined the synergies between the segments are evident: the waste produced by some segments becomes raw material for other segments thus creating a double economic advantage for the company: on the one hand, the costs of waste disposal are eliminated (in both the dairy and the farmhouse) on the other, the costs of purchasing raw materials and consumables of some segments are reduced since they are obtained by recycling, converting and reusing waste materials from other segments. There is also an NBS advantage that is achieved with other companies (farms operating within the same ecosystem) from which the company under examination purchases manure to transform it into electricity through the biogas plant. In addition to minimising their environmental impact, these transactions generate significant reciprocal economic benefits. In particular, those that use manure and wastewater from stables not only generate revenues by selling electric energy but also do not pay waste disposal expenses. The company examined in this paper achieves the advantage of obtaining raw materials at a very low cost, i.e. manure and wastewater from the stables, which is needed to produce electricity using the biogas plant that enters the national electricity grid, achieving substantial revenue flows (on average $€ 2.1$ million per year). 
Integrated segment reporting allows measurement of the added value of these segments, that is, the wealth they produce, and which may be distributed to meet the interests of stakeholders. Furthermore, when integrated segment reporting is prepared by a company that implements an NBS model, it highlights the benefits that derive from it in terms of costs and revenues for each distinct segment. Following the literature review, in the next section, we will examine the case study.

\section{The Research Case of Fattoria della Piana: Methodology, Mission and Governance}

\section{Methodology}

This section presents a research case [38-40], the analysis of which is performed through a qualitative approach [41]. The case was chosen because it is a "critical case" [39]. In fact, it is of significant importance for the positive results that the company has achieved to date in the concrete implementation of an NBS model. These results derive from the transformation of agri-food and zootechnical production waste into resources in an efficient and economical way. This process demonstrates the concrete possibility of combining the reduction of the environmental impact of production activities, good economic, social and environmental results. To this must also be added the satisfaction of the stakeholders through the distribution of a substantial added value and the adoption of NBS.

The research was conducted by adopting the participant observation method, a variant of the case method, which leads the researcher to observe the reality by interacting with the key players of the company. The results are also based on documentary analysis, used to collect, classify, measure and interpret information [42]. The examined documents made it possible to give definition to the map of the segments and to allocate costs and revenues to these centres and in this way to measure their gross and net added value and operating result. Accounting and non-accounting information was used, acquired directly from the managers. The latter also assessed the consistency of the results of the segments reached through the allocation of costs and revenues to these result centres. We are fully aware that general theories, valid for all companies, cannot be inferred from cases [42, 43]. In fact, this study does not aim to build a "theoretical case" [38] from which to derive a theory by means of a statistical generalisation or mathematical modelling [39, 44, 45], but it has more limited objectives: establishing a theoretical framework of reference for companies operating in this sector who intend to carry out reporting by segment for management control and also external communication needs and demonstrating the economic convenience of adopting an NBS model in the agri-food and zootechnical fields. In fact, the segment report presented in this paper can also be adopted, with the necessary adjustments, by other companies operating in the same fields of activity. By carrying out a similar activity they face similar management problems, the adaptation of the report schemes by segment presented in this paper to the needs of each company is minimal. For the description of the case we use the mission, governance and accountability scheme proposed by Matacena. 


\section{Mission and Governance}

For the description of the case we use the mission, governance and accountability scheme [46]. Fattoria della Piana is a cooperative of agricultural products, established in 1986, with registered offices in Candidoni (RC-Italy). The company's mission is to produce mainly dairy products with the aim of respecting the traditions of the Calabrian territory with the combination of modern technologies to respect the environment, giving life to the NBS aspects related to: Reduce; Reuse; Recycle $^{1}$ [16].

It operates in the dairy sectors, collecting the milk produced by the members of the cooperative and transforming it into dairy products that it distributes daily using fresh products, its agritourism activity and energy and heat production chain through a biogas plant and a photovoltaic plant. The cooperative created an efficient NBS model by transforming the problems of the disposal of livestock rubbish and dairy processing residues into resources to produce electricity and heat, through a biogas plant with a power of $998 \mathrm{~kW}$, in water that can be used to irrigate the fields in which food for farm animals is grown, through a phytodepuration plant, in fertilizer to fertilize the fields in which forage for animals grows.

The company has obtained ISO 14001 certification, which is issued to companies that are able to control the effects of their production activities, minimizing the environmental impact and won a lot of awards (fattoriadellapiana.it). The cooperative's governance considers the typical aspects of these companies, namely: mutuality, democracy and solidarity, which are reflected in the active participation of employees at various levels. After the brief analysis of mission and governance, we can consider the different dimensions of NBS and add the segments that will be explained in the following section.

\section{The Case Study "Fattoria della Piana": NBS and Integrated Segment Reporting}

In the case study examined, Fattoria della Piana, the segment with the highest turnover in 2017 and 2018, is a "Dairy", together with the segments of: "Electricity production from biogas plant", "Electricity production from a photovoltaic plant" and "Farmhouse".

The biogas plant collects the manure of the livestock farms in the area, especially one located in an area adjacent to the farm examined in this case study, and the discharges of the dairy processing (mostly whey) into two large fermentation tanks that

\footnotetext{
1 "Today ours is the largest farm in the province of Reggio Calabria and one of the largest in Southern Italy. A reality that continues to grow, always respecting the environment and transforming what is normally waste into a resource. Our organic fertilizer returns to the soil all the nutrients necessary to obtain quality productions. We replicate natural cycles by generating more energy than is necessary for the operation of the company, helping to reduce the environmental impact. We have a photovoltaic system that powers the entire farm and allows you to cut costs. We have a biogas production plant powered by different processing residues, which allows you to create biomethane. Finally, there is our phytodepuration plant, the largest in Southern Italy. The electricity produced by biomethane, equal to $998 \mathrm{~kW} / \mathrm{h}$, is fed into the national grid, covering the energy needs of 2,680 families." (www.fattoriadellapiana.it).
} 
transform these waste materials into biogas. The biogas thus obtained is burned to produce electricity which is sold to the national electricity company. The "Dairy" and the "Farmhouse" segments are self-sufficient as regards electrical energy and heat need thanks to the photovoltaic plant, built using solar panels applied onto the roofs of the farm. The fermentation residue of the biogas plant is transformed into fertilizer which is used to grow fodder. Biomasses (basically manure and sewage deriving from cattle breeding and milk processing) pose the ecological and economic problems of their disposal. The NBS model adopted by the company examined allows these problems to be transformed into profit and cost-saving opportunities. On the one hand, there are substantial cost savings since the companies participating in this NBS model do not pay the following costs: disposal and treatment of manure, sewage and discharges from the farm and dairy, since they are used as raw material for the biogas plant; water for irrigation purposes, provided by the phytopurification of waste water and farm and dairy drains; fertilizers, obtained as a residue from the fermentation of biomass in the biogas production plant; electricity and heat of the dairy and the farmhouse, thanks to the photovoltaic plant.

By reclassifying the accounting data, the following reporting by segment scheme was developed. It is based on the value-added model, which highlight the gross and net added value and the operating result of the different segments and which make synergies between segments deriving from the adoption of the NBS model evident (Table 1).

Table 1. The reporting by segment scheme adopted in the case study

\begin{tabular}{|c|c|c|c|c|c|c|c|c|c|c|}
\hline \multirow[t]{2}{*}{$\begin{array}{l}\text { Revenues and } \\
\text { costs }\end{array}$} & \multicolumn{2}{|c|}{ Biogas plant } & \multicolumn{2}{|c|}{$\begin{array}{l}\text { Photovoltaic } \\
\text { plant }\end{array}$} & \multicolumn{2}{|c|}{ Dairy factory } & \multicolumn{2}{|c|}{ Farmhouse } & \multicolumn{2}{|l|}{ Total } \\
\hline & 2017 & 2018 & 2017 & 2018 & 2017 & 2018 & 2017 & 2018 & 2017 & 2018 \\
\hline \multicolumn{11}{|l|}{ Sales } \\
\hline $\begin{array}{l}\text { Segment } \\
\text { sales/Total sales }\end{array}$ & $26 \%$ & $27 \%$ & $2 \%$ & $1 \%$ & $70 \%$ & $70 \%$ & $3 \%$ & $2 \%$ & $100 \%$ & $100 \%$ \\
\hline $\begin{array}{l}\text { Net value added } \\
\text { of the } \\
\text { segment/Sales of } \\
\text { the segment }\end{array}$ & $16 \%$ & $37 \%$ & $26 \%$ & $17 \%$ & $12 \%$ & $11 \%$ & $61 \%$ & $64 \%$ & & \\
\hline $\begin{array}{l}\text { Net value added } \\
\text { of the } \\
\text { segment/Total } \\
\text { net value added }\end{array}$ & $29 \%$ & $50 \%$ & $3 \%$ & $1 \%$ & $58 \%$ & $41 \%$ & $10 \%$ & $7 \%$ & $100 \%$ & $100 \%$ \\
\hline $\begin{array}{l}\text { Operating result } \\
\text { of the } \\
\text { segment/Sales of } \\
\text { the segment }\end{array}$ & $15 \%$ & $33 \%$ & $26 \%$ & $17 \%$ & $4 \%$ & $0 \%$ & $10 \%$ & $-2 \%$ & & \\
\hline
\end{tabular}

The biogas production plant also generates an annual turnover of more than $€ 2.1$ million (26\% in 2017 and $27 \%$ in 2018 of the total sales of the company) through the transfer of electrical energy to the national electricity grid. In addition, the photovoltaic system also feeds electricity into the national electricity grid, generating a turnover of just over $€ 120,000$. While the dairy contributes a very high percentage to the corporate 
added value, only a low percentage of the revenues become operating profit. This means that added value is mainly used for employee remuneration.

It is evident the relevance of this integrated segment reporting which highlights for each segment the economic performance, in terms of operating result, and the social performance, in terms value-added, provided for management (internal reporting by segment) and for stakeholders (external reporting by segment).

\section{Discussion and Conclusion}

This paper has the objective of answering the research question: How to implement integrated segment reporting using the NBS perspective? Following the initial implementation of integrated segment reporting in the "Fattoria della Piana" case, we can find that the dimensions underlined regarding NBS find the case very interesting result regarding the surrounding area in which the case is. This is shown by the certifications that represent annual recognition of the activity of this farm. Concerning the different dimensions of NBS: reduce, recycle and reuse, in the case analysed we found a very interesting relationship among them. The implementation of segment reporting is confirming the increase of the value added in each segment and the positive trend of environmental behavior using the value added by segment (Table 2).

Table 2. Segment Reporting, NBS initial results from "Fattoria della Piana"

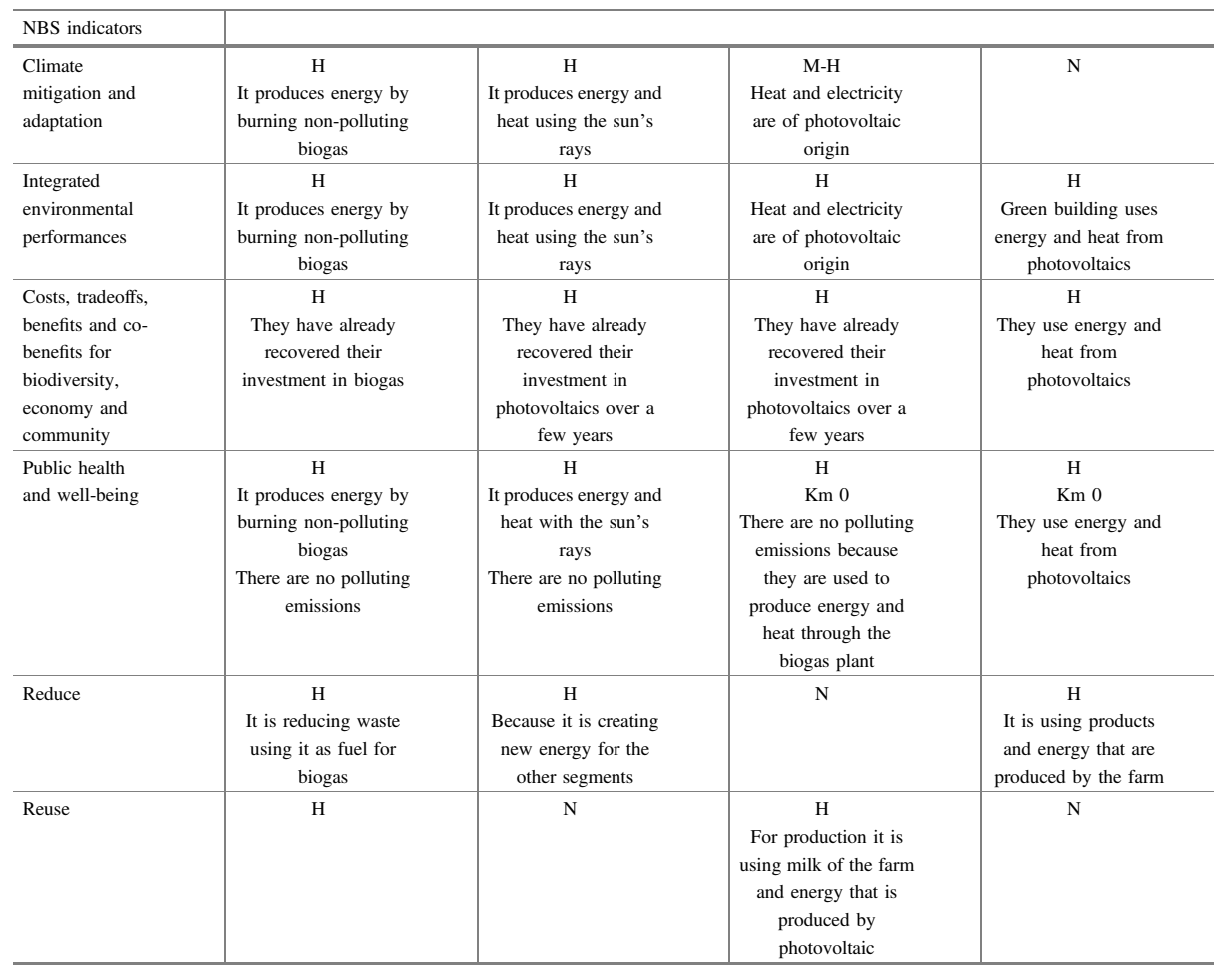


Table 2. (continued)

\begin{tabular}{|c|c|c|c|c|c|c|c|c|}
\hline \multicolumn{9}{|l|}{ NBS indicators } \\
\hline Recover & \multicolumn{2}{|c|}{$\mathrm{H}$} & \multicolumn{2}{|c|}{$\mathrm{N}$} & \multicolumn{2}{|c|}{$\mathrm{N}$} & \multicolumn{2}{|c|}{$\mathrm{N}$} \\
\hline \multirow{2}{*}{$\begin{array}{l}\text { Net value added } \\
\text { of the } \\
\text { segment/Sales } \\
\text { of the segment }\end{array}$} & 2017 & 2018 & 2017 & 2018 & 2017 & 2018 & 2017 & 2018 \\
\hline & $16 \%$ & $37 \%$ & $26 \%$ & $17 \%$ & $12 \%$ & $11 \%$ & $61 \%$ & $64 \%$ \\
\hline
\end{tabular}

Source: our elaboration (H: high; M: medium; N: neutral)

The combination of the drivers and dimension of NBS [16, 47] defined the qualitative approach and analysis of the case and we gave some explanations regarding how the management of each area is developing. Moreover, it is interesting to add the quantitative measurements by segment and we consider the added value determined by them, that is important in order to give such information as accountability of the economic implications of NBS behaviour of the farm. Therefore, to consider them in terms of NBS, we can affirm, regarding the answer to the research question, that the company is improving its environmental protection aspects through the segments and therefore of climate mitigation and adaptation.

The first results are limited because more information is needed to deeply analyse the environmental and social impact of "Fattoria della Piana".

Acknowledgment. This research is part of the TREnD project (Transition with Resilience for Evolutionary Development), which has received funding from the European Union's Horizon 2020 research and innovation program under the Marie Skłodowska-Curie grant agreement No. 823952.

\section{References}

1. Greer, J., Bruno, K.: Greenwashing the Reality Behind Corporate Environmentalism. Third world Network, Penang, Malaysia (1997)

2. Giannessi, E.: Le aziende di produzione originaria. Le aziende agricole. Pisa, Cursi (1960)

3. Besta, F.: La Ragioneria, vol. I, II e III. Villardi, Milano (1916)

4. Vermiglio, F.: Il bilancio sociale nel quadro evolutivo del sistema d'impresa. Grafo Editor, Messina (1984)

5. Matacena, A.: La responsabilità sociale e la comunicazione sociale nelle aziende nonprofit. In: Hinna, L. (a cura di) Il bilancio sociale. Il sole 24Ore, Milano (2002)

6. Rusconi, G.: Impresa, accountability e bilancio sociale. In: Hinna, L. (a cura di) Il bilancio sociale, pp. 229-268. Il Sole24ore, Milano (2002)

7. Gray, R., Adams, C.A., Owen, D.: Accountability, Social Responsibility and Sustainability. Pearson Education Limited, London (2014) 
8. Bebbington, J., Unerman, J.: Achieving the United Nations Sustainable Development Goals: an enabling role for accounting research. Accounting, Auditing \& Accountability Journal 31 (1), 2-24 (2018)

9. Dillard, J.: Speech presented at the CSEAR Conference Urbino (2018)

10. Ferraris Franceschi, R.: L'indagine metodologica in economia aziendale. Giuffrè, Milano (1978)

11. Naumes, W., Naumes, M.J.: The Art and Craft of Case Writing. Routledge, New York (2014)

12. Cohen-Shacham, E., Walters, G., Janzen, C., Maginnis, S.: Nature-based solutions to address global societal challenges, p. 97. IUCN, Gland, Switzerland (2016)

13. Raymond, C.M., Frantzeskaki, N., Kabisch, N., Berry, P., Breil, M., Nita, M.R., Calfapietra, C.: A framework for assessing and implementing the co-benefits of nature-based solutions in urban areas. Environ. Sci. Policy 77, 15-24 (2017)

14. Marchi, L.: I sistemi informativi aziendali, II edn. Giappichelli, Torino (1993)

15. Korhonen, J., Nuur, C., Feldmann, A., Birkie, S.E.: Circular economy as an essentially contested concept. J. Clean. Prod. 175, 544-552 (2018)

16. Kirchherr, J., Reike, D., Hekkert, M.: Conceptualizing the circular economy: an analysis of 114 definitions. Resour. Conserv. Recycl. 127, 221-232 (2017)

17. Nicolò, D.: Il reporting per segmenti e l'informativa settoriale secondo l'IFRS 8. Giuffrè, Milano (2009)

18. Barbato Bergamin, M.: Programmazione e controllo in un'ottica strategica. UTET, Torino (1997)

19. Riccaboni, A.: Gerarchia degli obiettivi d'impresa e sistema di gestione delle performance. Egea, Milano (1993)

20. Amigoni, F.: Le forme di reporting e l'analisi degli scostamenti. In: Amigoni, F. (a cura di) Misurazioni d'azienda. Programmazione e controllo. Giuffrè, Milano (1995)

21. Saita, M.: Programmazione e controllo. Giuffrè, Milano (1996)

22. Ferraris Franceschi, R.: Pianificazione e controllo. Sistemi di management e logiche di funzionamento, vol. I. Giappichelli, Torino (2007)

23. Marasca, S., Marchi, L., Riccaboni, A.: Controllo di gestione. Metodologie e strumenti. Knowità, Milano (2013)

24. Paris, A.: Comunicazione d'impresa e report di segmenti operativi. Cedam, Padova (1999)

25. Angiola, N.: IAS 14: Segment reporting. Interpretazione e applicazione. FrancoAngeli, Milano (2004)

26. Angiola, N.: IFRS 8: Operating segment. Riflessioni sui nuovi orientamenti. FrancoAngeli, Milano (2007)

27. Fortuna, F.: Il segmental reporting nel processo informativo d'impresa: comunicazione interna, esterna e creazione di valore. FrancoAngeli, Milano (2004)

28. Bugeja, M., Czernkowski, R., Moran, D.: Did IFRS 8 increase segment disclosure? Working Paper, University of Technology, Sydney, Australia, pp. 4-8 (2012)

29. Crawford, L., Extance, H., Helliar, C., Power, D.: Operating Segments: The Usefulness of IFRS 8. ICAS - Institute of Chartered Accountants in Scotland, Edinburgh (2012)

30. Mardini, G., Crawford, L., Power, D.: The impact of IFRS 8 on disclosure practices of Jordanian listed companies. J. Account. Emerg. Econ. 2(1), 67-90 (2012)

31. Pisano, S., Landriani, L.: The Determinants of segment disclosures: an empirical analysis on Italian listed companies. Financ. Report. 1(1), 113-132 (2012)

32. Nichols, N., Street, D., Cerola, S.: An analysis of the impact of adopting IFRS 8 on the segment disclosures of European blue-chip companies. J. Int. Account. Audit. Taxat. 21(2), 79-105 (2012) 
33. Nichols, N., Street, D., Tarca, A.: The impact of segment reporting under the IFRS 8 and SFAS 131 management approach: a research review. J. Int. Financ. Manage. Account. 24(3), 261-312 (2013)

34. Pardal, P., Morais, A.I., Curto, J.D.: Competitive harm and business segment reporting under IFRS 8: evidence from European union listed firms. In: EAA 38th Annual Congress, Glasgow, April 28-30, 2015, pp. 1-52 (2015)

35. Baldarelli, M.G., Nicolò, D.: Toward an integrated segment reporting: between tradition and innovation. Int. J. Adv. Manage. Econ. 08(06), 16-22 (2019)

36. Nicolò, D.: Il reporting per segmenti nel controllo di gestione. Un'esperienza nel settore delle autolinee di trasporto pubblico. In Corbella, S., Marchi, L., Rossignoli, F. (a cura di) Nuove frontiere del reporting aziendale. La comunicazione agli stakeholders tra vincoli normativi e attese informative, pp. 175-195. FrancoAngeli, Milano (2018)

37. Nicolò, D., Valenza, G.: Il reporting per segmenti nei settori del trasporto pubblico locale e della cura della salute. Esperienze a confronto, Management Control (in press)

38. Naumes, W., Naumes, M.J.: Art and Craft of Case Writing. ME Sharpe, Inc., Armonk (2006)

39. Yin, R.K.: Case Study Research and Applications: Design and Methods. Sage, Thousand Oaks (2013)

40. Chiucchi, M.S.: Il metodo dello studio di caso nel management accounting. Giappichelli, Torino (2012)

41. Ritchie, J., Lewis, J.: Qualitative Research Practice. A Guide for Social Science Students and Researchers. Sage, Thousand Oaks (2003)

42. Costa, M.: Il caso in economia aziendale: tra logica della scoperta scientifica e logica della conferma scientifica. In: Dagnino, G.B., Di Betta, P., Quattrone, P. (a cura di) Le metodologie della ricerca nelle discipline economico-aziendali fra tradizione e nuove tendenze, pp. 421-447. Edizioni Scientifiche Italiane, Napoli (1998)

43. Corbetta, P.: Metodologie e tecniche della ricerca sociale, II edn. Il Mulino, Bologna (2014)

44. Klandermans, B., Staggenborg, S. (eds.) Methods of Social Movement Research, vol. 16. University of Minnesota Press, Minneapolis (2002)

45. Turrini, A.: Il caso come metodologia di ricerca in economia aziendale. In: Azienda Pubblica, vol. 15(1/2), pp. 67-85 (2002)

46. Matacena, A.: Corporate social responsibility and accountability: some glosses. In: Civil Economy, Democracy, Transparency and Social and Environmental Accounting Research Role, pp. 7-59 (2010)

47. Cohen-Shacham, E., Walters, G., Janzen, C., Maginnis, S.: Nature-Based Solutions to Address Global Societal Challenges, p. 97. IUCN, Gland, Switzerland, (2016)

Open Access This chapter is licensed under the terms of the Creative Commons Attribution 4.0 International License (http://creativecommons.org/licenses/by/4.0/), which permits use, sharing, adaptation, distribution and reproduction in any medium or format, as long as you give appropriate credit to the original author(s) and the source, provide a link to the Creative Commons license and indicate if changes were made.

The images or other third party material in this chapter are included in the chapter's Creative Commons license, unless indicated otherwise in a credit line to the material. If material is not included in the chapter's Creative Commons license and your intended use is not permitted by statutory regulation or exceeds the permitted use, you will need to obtain permission directly from the copyright holder.

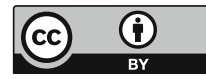

